\title{
SURGICAL APPROACH IN CONCOMITANT COMPLICATIONS OF DUODENAL ULCER
}

\author{
Nishanov F. ${ }^{1}$, Abdullajonov B. ${ }^{1}$, Nishanov M. ${ }^{1}$, \\ Rustamov J. ${ }^{1}$ Ibragimov B. ${ }^{1}$, Mishenina $E .^{2}$ \\ Andijan State Medical Institute, Republic of Uzbekistan ${ }^{1}$, \\ Kharkiv National Medical University, Ukraine ${ }^{2}$
}

\begin{abstract}
Authors analyzed results of surgical treatment in 307 patients with concomitant complications of duodenal ulcer.

Patients were divided into 2 groups according to the chosen diagnostic and therapeutic approach. The first group comprised 168 (54.7\%) patients who underwent "traditional" gastric resection while the second group included 139 (45.3\%) patients who underwent modifying variants of gastric resection.

Authors made a conclusion that improvement of definite operation types and employment of optimal treatment methods can result in a decrease in frequency of early postoperative "specific" complication by $8.3 \%$ (from 15.5 to $7.2 \%$, ð<0.01), frequency of re-laparotomy by 4.3 (from 6.5 to $2.2 \%$ ) and mortality by $2.2 \%$ (from 2.9 to $0.7 \%$, $\prec<0.05$ ), and this gives a possibility to improve the results of surgical treatment of concomitant complications of duodenal ulcers in whole.

Key words: gastric resection, main group, control group, re-laparotomy, modification variants.
\end{abstract}

Introduction. Up-to-date methods of complex conservative therapy both at in-patient and outpatient facilities have resulted in a decrease in the incidence of duodenal ulcer (DU), but they have not reduced frequency of complications requiring surgical interference. According to different authors, amount of complications of peptic ulcer comprises from 8 to $15 \%$, of all patients with gastro-duodenal ulcer [2, 3, 5, 8].

Concomitant complications of gastro-duodenal ulcer remain an urgent problem requiring further study. According to different authors, the incidence of concomitant complications varies from 25 to $30 \%$ from total number of patients with complicated gastro-duodenal ulcer [1, 4, 7, 9].

Improper administration of conservative antiulcer therapy, which often continues for a long time, even after the development of symptoms of complications, results in hospitalization of 48$75 \%$ patients to the surgical departments at late stages of the disease [6].

All the above determines the relevance of the conducted study.

Corresponding Author:

Mishenina Ekateryna, MD PhD,

Assistant of Department of Surgery 1

of Kharkiv National Medical University, Ukraine.

E-mail: dr.myshenina@gmail.com
2. PURPOSES, SUBJECTS and METHODS:

2.1. Purpose. To improve direct and remote outcomes of surgical treatment in patients with concomitant complications of DU by using organ saving operation with one-row sutures.

2.2. Subjects \& Methods. The study involved 1135 patients with complications of duodenal ulcer (DU) who were operated at the surgical department of Andijan State Medical Institute. Of them, 307 had concomitant complications of DU and were regarded as the material for the study.

The patients were divided into 2 groups according to the chosen diagnostic and surgical approaches. The first control group included 168 (54.7\%) patients, who were operated in the first period (1991-1996 yy. inclusive). The second main group comprised 139 (45.3\%) patients, who were operated in the second period (2010-2015 yy. inclusive). First group patients underwent "traditional" variant of gastric resection. The patient of the second group underwent modified variant of gastric resections.

Control group comprised 103 (61.3\%) male and $65(38.7 \%)$ female patients, in the main group 96 (69.1\%) were male and 43 (30.9\%) were female. 
In the main group 46 (14.9\%) were aged 2044 , the majority of patients, 198 (64.5\%) aged 45 to 59 .

The patients had ulcer from 1 to 21 years and more, on average 6.1 years and 32.9\% patients had ulcer for more than 5 years.

The nature and incidence of concomitant complications of ulcer in control group patients is presented in Table 1.

\section{RESULTS AND DISCUSSION.} Endoscopic examination showed that 191 (62.2\%) patients had damage of anterior wall of the duodenal bulb, 45 (14.6\%) patients had damage in the posterior wall and 71 (23.2\%) patients had damage in the lateral wall of the duodenum.

$\mathrm{X}$-ray examination of DU localization showed niche symptom or convergence of mucous folds in the place of cicatricial-ulcerative deformation

Table 1

The nature and incidence of concomitant complications of ulcer in patients in the group under investigation

\begin{tabular}{|c|c|c|c|c|c|c|}
\hline \multirow{3}{*}{$\begin{array}{l}\text { The character } \\
\text { of concomitant complications of DU }\end{array}$} & \multicolumn{4}{|c|}{ Groups of patients } & \multirow{2}{*}{\multicolumn{2}{|c|}{ Total }} \\
\hline & \multicolumn{2}{|c|}{ Control } & \multicolumn{2}{|c|}{ Main } & & \\
\hline & abs & $\%$ & abs & $\%$ & abs & $\%$ \\
\hline Bleeding+stenosis & 14 & 8.4 & 12 & 8.6 & 26 & 8.5 \\
\hline Bleeding + penetration & 17 & 10.2 & 15 & 10.8 & 32 & 10.4 \\
\hline Penetration + stenosis & 29 & 17.3 & 23 & 16.5 & 52 & 16.9 \\
\hline Penetration + perforation & 44 & 26.2 & 36 & 25.9 & 80 & 26.1 \\
\hline Penetration + stenosis & 56 & 33.3 & 49 & 35.4 & 105 & 34.2 \\
\hline Penetration + perforation + bleeding & 5 & 2.9 & 3 & 2.2 & 8 & 2.6 \\
\hline Penetration + perforation + bleeding + stenosis & 3 & 1.8 & 1 & 0.7 & 4 & 1.3 \\
\hline All patients & 168 & 100 & 139 & 100 & 307 & 100 \\
\hline
\end{tabular}

In control group such concomitant complications as bleeding + stenosis were found in $14(8.4 \%)$ cases, bleeding + penetration in adjacent organs in 17 (10.2\%) cases, penetration + stenosis in 29 (17.3\%) cases, penetration + perforation in 44 (26.2\%) cases and such concomitant complications as perforation + stenosis were detected in 56 (33.3\%) cases, penetration + perforation + bleeding in 5 (2.9\%) cases and penetration + perforation + bleeding + stenosis was found in $3(1.8 \%)$ cases.

In the main group such concomitant complications as bleeding + stenosis were found in $12(8.6 \%)$ cases, bleeding + penetration in adjacent organs in 15 (10.8\%) cases, penetration + stenosis in 23 (16.5\%) cases, penetration + perforation in 36 (25.9\%) cases and such concomitant complications as perforation + stenosis were found in 49 (35.4\%) cases, penetration + perforation + bleeding in $3(2.2 \%)$ and penetration + perforation + bleeding + stenosis in $1(0.7 \%)$ cases.

Before operation patients underwent instrumental examination including esophagogastroduodenoscopy (endoscopic device PENTAX OS-A79), radiography with contrast medium and ultrasound study. Laboratory examination comprised routine clinical and biochemical blood and urine test, assessment of blood coagulation system.

Conflict of interests. There is no conflict of interests. in 247 (80.4\%) patients. Deformation of the bulbs of duodenum was found in 231 (75.2\%) patients.

The study implied determination of evacuation function of the stomach, which was characterized by the rate of stomach emptying. The rate was classified as accelerated (evacuation time less than 1 hour), normal ( $1 / 2-2$ hours) and decelerated evacuation (more than 2 hours).

Preoperative preparation of patients lasted for 7-10 days. During this period they underwent complex anti-ulcer therapy, correction of functional abnormalities of main internal organs, and replenishment of reserves of the body with intravenous saline and protein infusion, prescription of vitamins, etc.

Control group patients underwent such variants of anastomoses in "traditional" gastric resection as Bilroth-I gastroduodenal anastomosis; Gaberer-Finney's terminolateral anastomosis; Khachiev's terminolateral anastomosis; Gofmeyster-Finsterer's gastroenteral anastomosis; Balfur's gastroenteral aanastomosis; Ru's gastroenteral anastomosis.

Table 2 presents early post-operative "specific" complications in the control group depending on the type of operation.

As can be seen on the table, duodenal stump leakage was found in 4 (2.4\%) control group patients, bleeding from the area of anastomosis in 8 (4.7\%) and impairment of motor-evacuator functions (MEF) in 14 (8.4\%) patients. In control group 
Early "specific" complications in the control

Table 2 group depending on the type of gastric resection

\begin{tabular}{|l|c|c|c|c|c|c|c|c|}
\hline \multirow{2}{*}{$\begin{array}{c}\text { Types of gastric operation } \\
\text { with drainage }\end{array}$} & $\begin{array}{c}\text { Duodenal } \\
\text { stump } \\
\text { leakage }\end{array}$ & \multicolumn{2}{c|}{ Bleeding } & \multicolumn{2}{c|}{$\begin{array}{c}\text { MEF } \\
\text { abnormality }\end{array}$} & \multicolumn{2}{c|}{ Total } \\
\cline { 2 - 11 } & abs & $\%$ & abs & $\%$ & abs & $\%$ & abs & $\%$ \\
\hline Bilroth-I GDA, n=72 & - & - & 3 & 4.2 & 4 & 5.6 & 7 & 9.7 \\
\hline Khachiev's TLA, n=5 & - & - & - & - & 1 & 20.0 & 1 & 20.0 \\
\hline Gabeber-Finney's TLA, n=34 & - & - & 1 & 2.9 & 3 & 8.8 & 4 & 11.7 \\
\hline Gofmeyster-Finsterer's GEA, n=43 & 4 & 9.3 & 2 & 4.6 & 4 & 9.3 & 10 & 23.3 \\
\hline Balfur's GEA, n=6 & - & - & 1 & 16.6 & 1 & 16.6 & 2 & 33.4 \\
\hline Ru-Ibadov's GEA, n=8 & - & - & 1 & 12.5 & 1 & 12.5 & 2 & 25.0 \\
\hline Total, n=168 & 4 & 2.4 & 8 & 4.7 & 14 & 8.4 & 26 & 15.5 \\
\hline
\end{tabular}

patients complications associated with operative interference were observed in 26 (15.5\%) cases.

Main group patients underwent the following variants of drainage in modified gastric resection: Bilroth-I-Gaberer GDA; Gaberer-Finney's TLA; Khachiev's TLA; Gaberer-Gofmeyster-Finsterer's GEA; Gaberer-Ru-Ibadov's GEA.

Modified Bilrot-I-Gabeber gastric resection. Upper median laparotomy. Strong's operation is performed after inspection of the upper floor of the abdominal cavity. The procedure implies determination of gastric resection borders, assessment of DU condition and pathomorphologic changes, location of ulcer, possibility of its removal and possible type of anastomosis. Then Kocher's maneuver is performed to achieve strictly sidewall mobilization of the stomach and DU. Selective vagotomy is performed above the level of marked resection up to the esophagus. Gastric press is superimposed at the distance of $5-6 \mathrm{~cm}$ perpendicular to its axis on the part of the stomach being removed from the side of greater curvature,

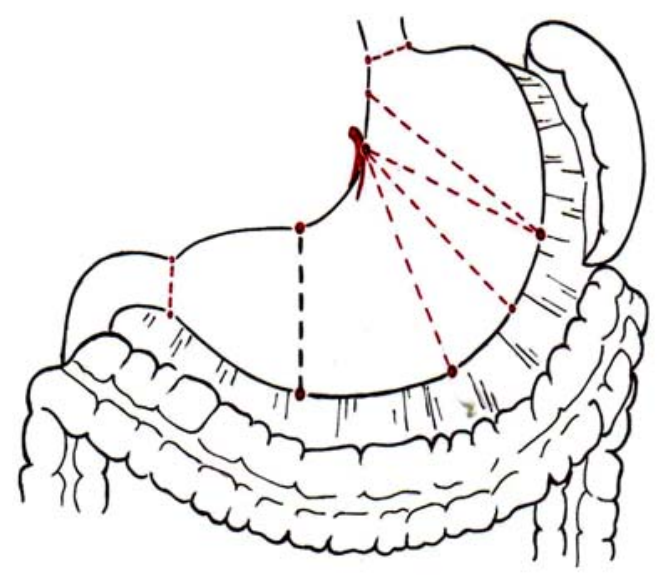

not getting to the lesser curvature. From the side of lesser curvature the second press is superimposed at 450 under angle to axis of the stomach. Then intersection of the lesser curvature under the second press is made with interrupted serosous-muscular-submucosal sutures in one row. Then serous membrane is incised $5-6 \mathrm{~mm}$ proximally from the first press and circular corrugating muscular-submucosal sutures are made, reducing the diameter of pylorus to 2.5$3 \mathrm{~cm}$. The gastric stump is excised between the press and sutures. Then interrupted serousmuscular sutures are made between the gastric stump and posterior wall of duodenum below the ulcer (Fig. 1).

The antral part of the stomach and part of the duodenum with ulcer are excised above them. Then anterior anastomosis lip is made by singlerow serous-muscular-submucosal sutures. The joint place of three sutures on lesser curvature is consolidated by a "P"-shaped suture. In the end anastomosis is checked for leakproofness and

Fig. 1. Mobilization and resection of the stomach (schematic representation) 
permeability. Figure 2 presents the final type of Bilroth-I-Gaberer-Finney modified gastric resection.

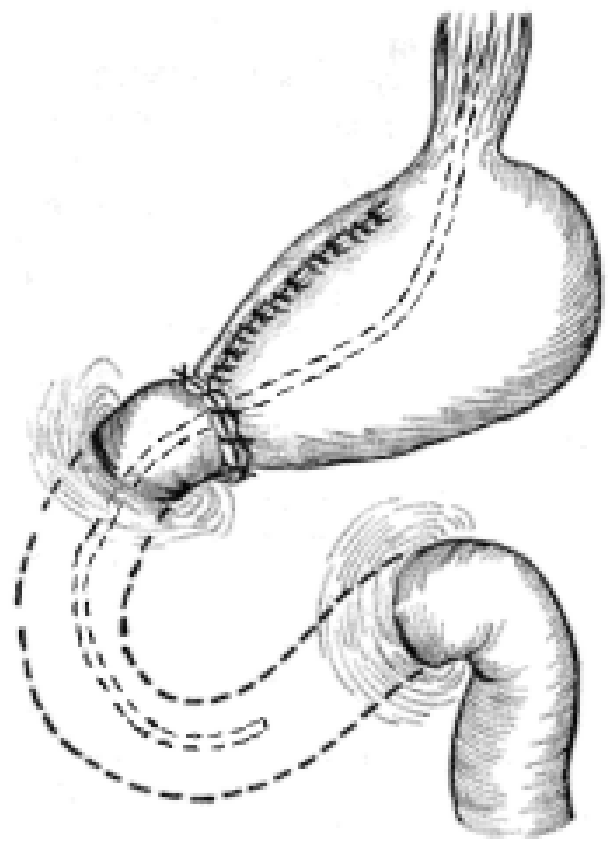

Fig. 2. The last form of modified Bilroth-I-Gabeber-Finney gastric resection

It should be noted that restriction of gastric resection by removing only antrum promotes conservation of the greater part of the stomach and allows imposing gastro-duodenal anastomosis without sutures.

Modified Gofmeyster-Finsterer's gastric resection. The gastric stump was formed as described above. Figure 3 presents final type of modified Gofmeyster-Finsterer's gastric resections.

Modified Gofmeyster-Finsterer's gastric resection involved updated methods for suturing duodenal stump. We have revised the operative techniques and reached to conclusion, that it must provide reliability of the stump coverture with minimal injury.

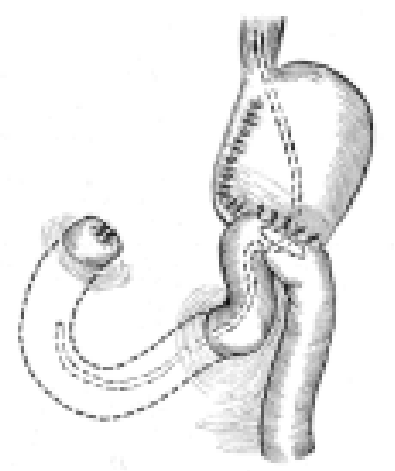

Fig. 3. The last form of modified Bilroth-IIGofmeyster-Finsterer gastric resection
Main group patients underwent 2 advanced methods for stump suturing, that enabled us to greatly spare duodenal tissue, and stump coverture in minimal pulling of tissue and slight mobilization of stump nearly excludes impairment of its blood circulation. Employment of internal drainage of stump provides reliability of the methods for prevention of duodenal stump leakage.

We use this modification of stump coverture in non-complicated and stenotic ulcers of duodenal bulb. In suturing duodenal stump it is necessary first to put 2 lateral serous-muscular sutures.

After fastening sutures the lateral sides of duodenal stump are invaginated inside and duodenal stump receives figure-of-eight form. Then "P"-shaped serous-muscular suture is put. Anterior and posterior walls of the stump are invaginated when fasting this suture.

Thus, duodenal stump is closed by interrupted single-row suture with invagination of first lateral, then anterior and posterior walls.

The advantage of this method is that singlerow suture is less invasive, spares tissue for closing stumps, and is simple. The mucous membrane of the intestine remains intact. Serous-muscular sutures allow to avoid infection of sutures by intestinal contents.

In "severe" ulcers, when there is even less unchanged tissue for closing the stumps, the technique for stump coverture is as follows: two semipurse-string sutures are put for duodenal stump coverture. Besides, the needle should enter at $0.2 \mathrm{~cm}$ from edge of the duodenal wall, and should exit at $0.5-0.7 \mathrm{~cm}$. Between the next entrance and exit of the needle the distance should also be $0.5-0.7 \mathrm{~cm}$. When closing the sutures the duodenal wall should be put inside.

Necessary condition of the using the said methods is identical internal draining of the duodenal stump. For this constant nasogastroduodenal probe is directly taken into the duodenal stump.

For timely repair of motor-evacuator functions of the intestine and correction of metabolic impairments we used probe enteral feeding (conducted secondary to early intestinal stimulation), which began on the $2^{\text {nd }}$ day and was carried out with poly-ionic solutions (mineral water). From the $3^{\text {rd }}$ day, nutritional mixtures were added. The need for plastic material was defined with provision for degree of the impaired metabolism and values of pathological losses. In absence of complications in the postoperative period, the probe was removed on the $6^{\text {th }}-7^{\text {th }}$ day. 
Main group patients had extended indications for modification of the first Bilroth technique, that is why percentage of resection with gastroduodenal anastomosis was increased from 53.9 to $78.7 \%$. Moreover, we decided to refuse from BalfurMayngot's gastric resections.

Indications for Bilroth-I-Gaberer gastroduodenal anastomosis included bulbous location of ulcers, absence of large peri-ulcerous chronic duodenal obstruction. In compensated and sub-compensated forms of chronic duodenal obstruction we performed correction by Strong's operation. One patient with decompensated degree of chronic duodenal obstruction underwent modified Ru-Ibadov's gastric resection (with invaginated entero-enteral anastomosis).

Table 3 presents early post-operate "specific" complications in the main group.

Table 3

Early "specific" complications in the main group related to gastric resection

\begin{tabular}{|l|c|c|c|c|c|c|c|c|}
\hline \multirow{2}{*}{$\begin{array}{c}\text { Types of operation } \\
\text { for gastric drainage }\end{array}$} & $\begin{array}{c}\text { Duodenal } \\
\text { stump } \\
\text { leakage }\end{array}$ & \multicolumn{2}{c|}{ Bleeding } & \multicolumn{2}{c|}{$\begin{array}{c}\text { MEF } \\
\text { impairment }\end{array}$} & \multicolumn{3}{c|}{ All } \\
\cline { 2 - 11 } & abs & $\%$ & abs & $\%$ & abs & $\%$ & abs & $\%$ \\
\hline Bilroth-I GDA, $\mathrm{n}=77$ & - & - & 1 & 1.3 & 2 & 2.6 & 3 & 3.9 \\
\hline Khachiev's TLA, $\mathrm{n}=8$ & - & - & - & - & 1 & 12.5 & 1 & 12.5 \\
\hline Gabeber-Finney's TLA, $\mathrm{n}=27$ & - & - & - & - & 1 & 3.7 & 1 & 3.7 \\
\hline Gofmeyster-Finsterer's GEA, $\mathrm{n}=23$ & 2 & 8.8 & 1 & 4.4 & 1 & 4.4 & 4 & 17.6 \\
\hline Balfur's GEA, $\mathrm{n}=0$ & - & - & - & - & - & - & - & - \\
\hline Ru-Ibadov's GEA, $\mathrm{n}=4$ & - & - & - & - & 1 & 25.0 & 1 & 25.0 \\
\hline Total, $\mathrm{n}=139$ & 2 & 1.4 & 2 & 1.4 & 6 & 4.3 & 10 & 7.2 \\
\hline
\end{tabular}

infiltrate and marked deformation of the initial part of the duodenum.

Identification of the peri-ulcerous infiltrate and deformation of the bulb was regarded as an indication for terminal-lateral anastomosis. We consider L.G.Khachiev's anastomosis is the most optimal, so in absence of changes in the anterior wall of the duodenum we tried to impose anastomosis by the given method. Besides, the lateral wall of duodenum had the smallest amount of changes and imposition of sutures was suitable, we performed Gaberer-Finney's terminal-lateral anastomosis.

The indications for Bilroth-II resection included large peri-ulcerous infiltrate, "low" and difficult to remove ulcers, and decompensation degree of
As can be seen from the table, in the main group duodenal stump leakage was observed in 2 (1.4\%) patients, bleeding from the area of anastomosis was found in 2 (1.4\%) patients and impairment of motor-evacuation function (MEF) in $6(4.3 \%)$ patients. In the main group complications related to surgical intervention in total comprised 10 (7.2\%) cases.

Modified gastric resection and correction of post-operative management reduced the percent of MEF impairments in main group patients from 1.8 to $0.7 \%(r<0.05)$, and mortality in this complication from 0.6 to $0.0 \%(\mathrm{p}<0.01)$.

Comparison of the results of surgical treatment in both groups with concomitant complications of DU (table 4) gives a possibility

Table 4

Comparison of results of surgical treatment in the main and control group patients

\begin{tabular}{|l|c|c|c|}
\hline \multirow{2}{*}{\multicolumn{1}{|c|}{ Patients group }} & \multicolumn{2}{|c|}{ Groups of patients } & \multirow{2}{*}{$\begin{array}{c}\text { Improvement } \\
\text { of the results by }\end{array}$} \\
\cline { 2 - 3 } & $\begin{array}{c}\text { Control } \\
\mathrm{n}=168\end{array}$ & $\begin{array}{c}\text { Main } \\
\mathrm{n}=139\end{array}$ & \\
\hline Complications related & & & \\
to surgical intervention: & & & $2(1.0)$ \\
$\quad$ 1. Duodenal stump leakage & $4(2.4)$ & $2(1.4)$ & $6(3.3)$ \\
2. Bleeding & $8(4.7)$ & $2(1.4)$ & $8(4.1)$ \\
3. MEF impairment & $14(8.4)$ & $6(4.3)$ & $16(8.3)$ \\
\hline All complications & $26(15.5)$ & $10(7.2)$ & $8(4.3)$ \\
\hline Re-laparotomy & $11(6.5)$ & $3(2.2)$ & $4(2.2)$ \\
\hline Mortality & $5(2.9)$ & $1(0.7)$ & \\
\hline
\end{tabular}


to draw a conclusion that in the main group of patients we were able to reduce the incidence of complications related to surgical intervention, frequency of re-laparotomy and mortality rate.

Conclusion. Elaborated by the authors and updated separate surgical techniques as well as employment of optimal ways for the treatment of complications allowed to reduce the incidence of early post-operative "specific" complications by $8.3 \%$ (from 15.5 to $7.2 \%$, $\mathrm{p}<0.01$ ), frequency of re-laparotomy by 4.3 (from 6.5 to $2.2 \%$ ) and mortality rate by $2.2 \%$ (from 2.9 to $0.7 \%, \mathrm{p}<0,05$ ), therefore, promoting improvement of the results of surgical treatment of concomitant complications in patients with duodenal ulcers.

\section{References}

1. Afendulov, S.A. (2005). Treatment of penetration ulcers, M.: FGUP IPS Finopol, 166

2. Babadjanov, B.P., Tajibayev, O.B. K (2001). Marks typology and surgical treatment in plural cankers of the stomach. Conference materials "Modern technology of the general surgery". Moscow, 146-147.

3. Bondarov, V.I. (2004). Direct and remote results with using piloro saving and piloro reability operations with complex surgigal treatments perforative piloro-duodenal ulcers. Clinic surgery, 2, 39-42.

4. Verbiskiy, V.G., Bagnenko, S.F., Kurigin, A.A. (2004). "Bleeding of alimentary tract with ulcer etiology". Politechnic, SPb,242.

5. Juravlev, G.U. (2006). Ways of improvement results surgical treatments patients with ulcer diseases pyloric part and duodenum: Autoreferate. dis. ... med. Sub, Voronej, $44 \mathrm{p}$.

6. Kalinin, A.V. (2002). Ulcer disease: from pathogenesis to the therapy. Farmateka, 9, 3-10.

7. Onopriev, V.I. (2006). New conception, tactic and technology surgical treatments complications of the duodenal ulcers. Bulletin surgical gastroenterology, 1, 11-16.

8. Barkun, A., Bardou, M., Ernst, J. (2010). International Consensus Recommendations on Management of patients With Novariceal Upper Gastrointestinal Bleeding. Ann. Inter. Med, 152, 101-113.

9. Griffiths, E.A., McDonald, C.R., Bryant, R.V. (2014). Retrospective analysis of surgery and transarterial embolization for major non-variceal upper gastrointestinal bleeding. ANZ J. Surg, 3.

Received: 01-Jun. - 2017

Accepted: 12-Nov. - 2018 